\title{
A Case of Severe Exercise Associated Hyponatremia after Running Marathon
}

\author{
Harriet Hoi-Yan Kong ${ }^{1}$, Hon-Lok Tang ${ }^{2 *}$, Jacky Man-Ho Wong ${ }^{3}$ and Samuel Ka-Shun Fung ${ }^{2}$ \\ ${ }^{1}$ Department of Medicine and Geriatrics, Caritas Medical Center, Hong Kong \\ ${ }^{2}$ Division of Nephrology, Department of Medicine and Geriatrics, Princess Margaret Hospital, Hong Kong \\ ${ }^{3}$ Department of Medicine, Yan Chai Hospital, Hong Kong
}

*Corresponding author: Dr. Hon-Lok Tang, Division of Nephrology, Department of Medicine and Geriatrics Princess Margaret Hospital, 2-10 Princess Margaret Hospital Road, Lai Chi Kok, Kowloon, Hong Kong; Tel: 852-29903415; Fax: 852-29903453; Email: tanghl@ha.org.hk

Received: December 22, 2020; Accepted: December 26, 2020; Published: December 27, 2020

\begin{abstract}
Exercise associated hyponatremia (EAH) can cause serious neurological manifestations. We report a case of EAH presented with convulsion and drowsiness after running marathon. The patient's plasma sodium level on presentation was 119 mmol/L. He was given intravenous hypertonic saline infusion for 2 times. His conscious level improved after hypertonic saline and plasma sodium level corrected. He regained full consciousness 3 days after admission and was discharged in good condition. In this report, we reviewed the underlying pathophysiology, clinical features, risk factors, prevention measures, and treatment options of this disease entity. Early recognition of this disease entity and timely treatment with hypertonic saline is life saving.
\end{abstract}

\section{Background}

Exercise associated hyponatremia (EAH) is not uncommon and can cause serious neurological manifestations and even death. Early recognition of the diagnosis and timely treatment can be life saving. We here report a case of EAH and review the management for this disease entity.

\section{Case Report}

A 39-year-old gentleman with good past health was admitted to Princess Margaret Hospital after developing an episode of tonic clonic seizure. On the day of admission, he had been participating in a marathon run from 8:30 am till 4:30 pm. He did not have any fever, headache, neck pain, photophobia, weakness or numbness beforehand. He took an over-the-counter "Japanese medication" before the race, which was suspected to be a non-steroidal antiinflammatory drug (NSAID). Otherwise he did not have any history of drug abuse or herbal medication consumption. He had no family or personal history of epilepsy.

On arrival at the emergency department, the patient was drowsy with Glasgow Coma Scale (GCS) of E2V1M4. His seizure had aborted spontaneously. He was normothermic with stable hemodynamics. Blood pressure was $135 / 75 \mathrm{mmHg}$ and pulse $65 / \mathrm{min}$. His spot glucose was $8.6 \mathrm{mmol} / \mathrm{L}$. On physical examination, he was well hydrated. His pupils were equal and reactive to light and there were no focal neurological deficits or meningism. ECG and CXR were unremarkable. CT brain showed mild cerebral edema. Blood tests revealed a plasma sodium $(\mathrm{Na})$ level of $119 \mathrm{mmol} / \mathrm{L}$. His plasma potassium, urea, creatinine, and creatinine kinase were $3.4 \mathrm{mmol} / \mathrm{L}$,
$7.2 \mathrm{mmol} / \mathrm{L}, 85 \mu \mathrm{mol} / \mathrm{L}$, and $2732 \mathrm{U} / \mathrm{L}$ respectively. Urine myoglobin was negative. White cell count was $17 \times 10^{9} / \mathrm{L}$, otherwise the complete blood count and liver function tests were normal. Further workup for hyponatremia were performed. Paired plasma osmolality, urine osmolality, and spot urine sodium checked 5 hours later were 244 $\mathrm{mmol} / \mathrm{Kg}, 580 \mathrm{mmol} / \mathrm{Kg}$, and $46 \mathrm{mmol} / \mathrm{L}$ respectively. There were no adrenal insufficiency or hypothyroidism.

Hypertonic saline (HTS) $20 \mathrm{ml} 5.85 \%$ sodium chloride $(\mathrm{NaCl})$ in $100 \mathrm{ml}$ normal saline infused intravenously over 2 hours was given for 2 times. The patient's conscious level improved as the plasma sodium level was corrected and his plasma sodium level normalized to 137 $\mathrm{mmol} / \mathrm{L}$. He regained full consciousness 3 days after admission and was subsequently discharged home on the third day.

\section{Discussion}

\section{Incidence}

Exercise associated hyponatremia is defined as hyponatremia that occurs during or up to 24 hours after physical activities, especially after endurance events [1]. It has been reported in marathons, military training, long distance hiking, and even yoga [1]. It is unheard of until 1981, as historically, runners are advised to restrict fluid intake during races [2]. After 1981, runners were advised to consume as much fluid as possible, so asymptomatic EAH is common with an incidence of $12-15 \%[3,4]$, and up to $50 \%$ among ultramarathon runners $[5,6]$. Symptomatic EAH is less common with incidence range from $0.1-1 \%$ [6,7], but can be as high as $38 \%$ in longer distance events [8]. Deaths are rare though, with only 14 reported in literature $[7,9]$. 


\section{Pathophysiology}

The mechanism leading to hyponatremia during exercise is mainly by dilution [7]. During exercise, fluid ingestion is driven by thirst and conditioned behavior. The abundant fluid supply during the race and the recommendation to drink in order to avoid dehydration can result in excessive fluid ingestion relative to fluid loss. The hypotonic replacement fluid results in an increase in total body water (TBW) relative to total body exchangeable sodium. Metabolism of glycogen store and triglyceride also produce free water. As a result, hyponatremia occurs due to dilution. Overhydration alone, however cannot fully explain the pathophysiology of EAH as hyponatremia can still occur in athletes who drink less than the maximum water excretion capacity [7]. This suggests that a defect in renal water excretion through an increase in antidiuretic hormone (ADH) also play a role in the development of EAH. ADH during exercise is not just stimulated by volume depletion, but also by other nonspecific stresses like physical exercise, pain, emotion, and cytokine release during muscle injury [10]. Therefore the ADH level can be inappropriately elevated during marathon running even when volume depletion is not present, resulting in hyponatremia [3]. Catecholamine and angiotensin II release during exercise may also impair the dilution capacity of the kidneys. This explained why the urine osmolality of our patient was inappropriately high.

Exchangable sodium stores also play a role in EAH. Although overhydration is a feature of $\mathrm{EAH}, 70 \%$ athletes with increased TBW did not develop hyponatremia in a study done by Noakes et al [7]. The author suggested that some people can mobilize osmotically inactive sodium from bone and cartilages so as to maintain normonatremia. EAH may develop if the body is unable to mobilize osmotically inactive sodium [7].

Overhydration is the number one risk factor for developing EAH as evident by a fall in the incidence after revising the upper limit of fluid consumption to 1-1.5 L/hour [11]. Intra-race weight gain is suggestive of overhydration. Participants with smaller body weight are also at risk as they tend to ingest more fluids relative to TBW [12]. Exercise duration of longer than 4 hours or in slow runners correlate with increased water consumption and increased sodium loss [13]. All these risk factors contribute to the development of hyponatremia in EAH. NSAID is also found to be associated with EAH in some studies by theoretically potentiating the effect of ADH [14-16]. Our patient ran for 8 hours and was suspected to have taken NSAID. He also had significant muscle injury as evident by the elevated creatinine kinase level, which might have further stimulated ADH release [10]. All these predisposed him to develop EAH.

\section{Clinical Features}

Most patients with EAH are asymptomatic or have non-specific symptoms like dizziness, nausea, and headache only. Symptoms are more likely to occur if $\mathrm{Na}<126 \mathrm{mmol} / \mathrm{L}$, but the rate and extend of the drop in extracellular tonicity are more important determinants [1]. Severe symptoms including confusion, seizure, and altered mental state are caused by cerebral edema secondary to hyponatremia. Respiratory distress due to non-cardiogenic pulmonary edema may also occur.

\section{Treatment}

Vigilance of the diagnosis is most important. Ideally, medical facilities at endurance events should be equipped to measure serum $\mathrm{Na}$. In the absence of $\mathrm{Na}$ level, empirical treatment should be initiated if clinically suspicious [9].

For asymptomatic patients, fluid restriction till urination is enough. If the serum $\mathrm{Na}<130 \mathrm{mmol} / \mathrm{L}$, oral HTS with $3 \% \mathrm{NaCl} 100$ $\mathrm{ml}$ or 4 broth cubes dissolved in $1 / 2$ cup water may be administered to reduce risk of progression to symptomatic EAH $[9,17]$. Mildly symptomatic patients should be given oral HTS $[9,17,18]$. Hydration with normal saline may cause further decrease in Na level if ADH level remain elevated and therefore should not be given until diuresis occur [17].

For severe symptomatic patients, HTS 3\% saline $100 \mathrm{ml}$ administered every 10 minutes until clinical improvement is recommended [17]. In patients with significant antidiuresis, higher dose of HTS 3-4 ml $/ \mathrm{kg} / \mathrm{hr}$ with administration of loop diuretics may be necessary [1]. In Hong Kong, we use 5.85\% (1 mmol/ml) HTS. Since EAH develops acutely, rapid correction of hyponatremia is safe and no cases of osmotic demyelination syndrome have been reported [17].

For the prevention of EAH, recommendation by the Statement of the Third International EAH Consensus Development Conference 2015 is to drink according to thirst [9]. Using the innate thirst mechanism to guide fluid consumption should limit drinking in excess and developing hyponatremia while providing sufficient fluid to prevent excessive dehydration [9]. Measuring serial body weights during training can guide the amount of fluid replacement. Sports drinks are hypotonic fluids and will not prevent EAH in runners who overdrink, as all sports drinks have a significant lower Na level (10-38 $\mathrm{mmol} / \mathrm{L})$ than serum $(\sim 140 \mathrm{mmol} / \mathrm{L})$ [9]. Education is the cornerstone for preventing EAH.

Timely administration of HTS is paramount in treatment of severe EAH. For those runners presenting with symptoms of severe EAH, emergent treatment with intravenous HTS is necessary and should not be delayed pending laboratory measurement of serum $\mathrm{Na}$ level [9]. Medical practitioners, especially medics who work at the field during endurance events should be well aware of this disease and be familiar with its treatment.

\section{References}

1. Rosner MH, Kirven J (2007) Exercise-associated hyponatremia. Clin J Am Soc Nephrol 2: 151-161.

2. Noakes TD (2003) Overconsumption of fluids by athletes. BMJ 327: 113-114.

3. Hew-Butler T, Dugas JP, Noakes TD, Verbalis JG (2010) Changes in plasma arginine vasopressin concentrations in cyclists participating in a $109-\mathrm{km}$ cycle race. $\mathrm{Br} J$ Sports Med 44: 594-597. [crossref]

4. Speedy DB, Noakes TD, Rogers IR, Thompson JM, Campbell RG et al. (1999) Hyponatremia in ultradistance triathletes. Med Sci Sports Exerc 31: 809-815. [crossref]

5. Lebus DK, Casazza GA, Hoffman MD, Van Loan MD (2010) Can changes in body mass and total body water accurately predict hyponatremia after a $161-\mathrm{km}$ running race? Clin J Sport Med 20: 193-199. [crossref] 
6. Hoffman MD, Hew-Butler T, Stuempfle KJ (2013) Exercise-associated hyponatremia and hydration status in 161-km ultramarathoners. Med Sci Sports Exerc 45: 784-791. [crossref]

7. Noakes TD, Sharwood K, Speedy D, Hew T, Reid S, et al. (2005) Three independent biological mechanisms cause exercise-associated hyponatremia: evidence from 2,135 weighed competitive athletic performances. Proc Natl Acad Sci U S A 102: 1855018555. [crossref]

8. Lee JK, Nio AQ, Ang WH, Johnson C, Aziz AR, et al. (2011) First reported cases of exercise-associated hyponatremia in Asia. Int J Sports Med 32: 297-302. [crossref]

9. Hew-Butler T, Rosner MH, Fowkes-Godek S, Dugas JP, Hoffman MD et al. (2015) Statement of the 3rd International Exercise-Associated Hyponatremia Consensus Development Conference, Carlsbad, California, 2015. Br J Sports Med 49: 1432-1446. [crossref]

10. Robertson GL (2006) Regulation of arginine vasopressin in the syndrome of inappropriate antidiuresis. Am J Med 119 (suppl 1): S36-42. [crossref]

11. Noakes TD, Speedy DB (2006) Case proven: exercise associated hyponatraemia is due to overdrinking. So why did it take 20 years before the original evidence was accepted? Br J Sports Med 40: 567-572. [crossref]
12. Almond CS, Shin AY, Fortescue EB, Maniix RC, Wypij D, et al. (2005) Hyponatremia among runners in the Boston Marathon. N Engl J Med 352: 1550-1556. [crossref]

13. Hew TD, Chorley JN, Cianca JC, Divine JG (2003) The incidence, risk factors, and clinical manifestations of hyponatremia in marathon runners. Clin J Sport Med 13: 41-47. [crossref]

14. Wharam PC, Speedy DB, Noakes TD, Thompson JM, Reid SA, et al. (2006) NSAID use increases the risk of developing hyponatremia during an Ironman triathlon. Med Sci Sports Exerc 38: 618-622. [crossref]

15. Ayus JC, Varon J, Arieff AI (2000) Hyponatremia, cerebral edema, and noncardiogenic pulmonary edema in marathon runners. Ann Intern Med 132: 711-714. [crossref]

16. Whatmough S, Mears S, Kipps C (2018) Serum sodium changes in marathon participants who use NSAIDs. BMJ Open Sport Exerc Med 4: e000364.

17. Hew-Butler T, Loi V, Pani A, Rosner MH (2017) Exercise-Associated Hyponatremia: 2017 Update. Front Med (Lausanne) 4: 21. [crossref]

18. Bridges E, Altherwi T, Correa JA, Hew-Butler T (2020) Oral Hypertonic Saline Is Effective in Reversing Acute Mild-to-Moderate Symptomatic Exercise-Associated Hyponatremia. Clin J Sport Med 30: 8-13. 